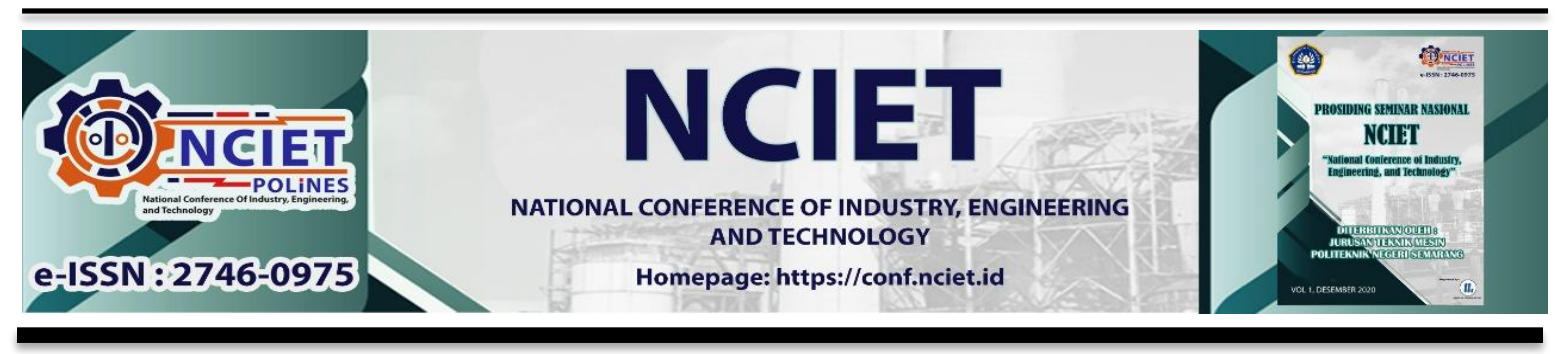

Prosiding Seminar Nasional NCIET Vol.1 (2020) B99-B110

$1^{\text {st }}$ National Conference of Industry, Engineering and Technology 2020,

Semarang, Indonesia.

\title{
RANCANG BANGUN COOLCASE PORTABEL MENGGUNAKAN MODUL TEC1-12710
}

\author{
Yusrizal Ashari $^{1}$, Widjonarko ${ }^{2}$, dan Bayu Rudiyanto ${ }^{1^{*}}$ \\ ${ }^{1}$ Jurusan Teknik, Politeknik Negeri Jember \\ Jalan Mastrip, Kotak Pos 164, Jember, 68121 \\ ${ }^{2}$ Jurusan Teknik Elektro, Universitas Jember \\ Jl. Kalimantan 37, Jember 68121 \\ *E-mail: bayu_rudianto@polije.ac.id
}

\begin{abstract}
Abstrak
Salah satu metode dalam penyimpanan makanan adalah menggunakan metode pendinginan makanan untuk menghambat mikroba pembusuk. Namun pendingin konvensional saat ini metode kompresi uap menggunakan freon. Selain itu dibutuhkan daya dan ruangan yang besar untuk menunjang performa dari kotak pendingin, oleh karena itu diperlukan inovasi untuk menciptakan kotak pendingin yang portabel, dan ramah lingkungan. Tujuan dari penelitian ini adalah merancang kotak pendingin yang portabel dan ramah lingkungan. Metode yang digunakan adalah merancang sistem pendingin dengan isolasi dan pengaturan temperatur dalam kotak pendinginmenggunakan modul termoelektrik, styrofoam sebagai konstruksi utama, plat aluminium sebagai kompartemen untuk meletakkan bahan uji, power supply sebagai sumber daya, dan Stepdown DC untuk memvariasikan tegangan yang masuk pada modul. Pengujian dilakukan dengan memperhatikan pengaruh performa pendinginan terhadap tegangan yang masuk pada modul dan temperatur maksimal yang dapat dicapai menggunakan isolasi medium air. Komponen yang digunakan modul TEC1-12710, dan air sebagai dinding isolasi. Hasil pengujian didapatkan bahwa supply tegangan berbanding lurus dengan performa pendinginan, dengan tegangan $12 \mathrm{~V}$ menjadi yang paling optimal, dengan pengambilan data selama 60 menit temperatur dalam kotak mencapai $24,5^{\circ} \mathrm{C}$ tanpa beban dan $24,56^{\circ} \mathrm{C}$ dengan beban air mineral 691 gram.
\end{abstract}

Kata Kunci: TEC1-12710; Power supply; Styrofoam; Stepdown DC; Aluminium.

\section{PENDAHULUAN}

Makanan dan minuman adalah satu dari hal pokok yang dibutuhkan manusia. Namun dalam penerapannya makanan membutuhkan perlakuan khusus untuk mencegah terjadinya pembusukan, perlakuan tersebut dapat dilakukan dalam berbagai cara, salah satunya adalah dengan proses pendinginan. Saat ini pendingin konvensional masih menggunakan bahan kimia yang bernama freon. Penggunaannya yang masif dan terbukti sangat dibutuhkan diperkirakan dalam tahun 2010 hingga 2015 akan meningkat hingga 49,8\% (Maulana, 2010). Kini pengembangan freon terus dikaji seperti yang dilakukan Fauzan (2015) dengan 
menggunakan freon tipe R-22 dan R-134A, bahwa temperatur yang terdapat pada fase evaporasi mendapatkan harga COP hingga 7,48 dengan temperatur mencapai $-5^{\circ} \mathrm{C}$. Namun dalam penggunaan freon itu tidak hanya memberikan dampak baik. Dikutip dari penelitian Etminan dkk (2014) saat ini zat freon diperkirakan berkontribusi dalam memberikan zat emisi setara karbon dioksida di atmosfer sebanyak 4\%, dan memiliki efek samping yang dapat menyebabkan perusakan ozon dan efek rumah kaca (Krisnadwi, 2015).

Beberapa cara telah dilakukan untuk mencari pendinginan alternatif, salah satunya adalah menggunakan modul termoelektrik yang memanfaatkan efek peltier. Pada penelitian yang dilakukan oleh Wirayudha (2012) termoelektrik dikombinasikan dengan Cryosurgery yakni alat kesehatan yang digunakan untuk menghancurkan jaringan dan sel yang rusak. Pada pengujiannya pada ujung atau end probe temperaturyang dapat dicapai sebesar $52,11^{\circ} \mathrm{C}$. Penelirian yang dilakukan oleh Delly, dkk (2016) pada hasil penelitian mereka jumlah kalor yang diserap modul termoelektrik mencapai $0,1524 \mathrm{~W}$ dari total jumlah panas sebesar $3,165 \mathrm{~W}$ dan penurunan temperatur dalam box mencapai $9^{\circ} \mathrm{C}$. Penelitian tentang modul termoelektrik terus dilakukan, diantaranya dengan melakukan variasi nilai tegangan yang masuk pada modul, didapatkan bahwa masuknya nilai tegangan berbanding lurus dengan performa dari modul termoelektrik (Nulhakim, 2017). Kemudian yang dilakuakn oleh Pourhedayat (2018) termoelektrik digunakan sebagai pendinginan air instan. Didapatkan bahwa nilai COP yang berhasil didapatkan dapat mencapai $>4$ dengan laju aliran 20L/h. Pengujian dengan kombinasi TEG (Termoelektrik Generator) dengan TEC (Termoelektrik Cooler) dilakukan untuk mengetahui pengaruh kemampuan dari TEG dengan melakukan pendinginan sisi panas pada TEG, disimpulkan bahwa pendinginan dari TEC tidak terlalu berpengaruh terhadap pendinginan sisi panas dari modul TEG.

Namun termoelektrik memiliki permasalahan dalam pembuangan panas. Efek peltier memiliki kelemahan yakni apabila dua plat logam dialiri listrik logam dapat menyerap kalor namun juga melepas kalor. Untuk mendapatkan performa yang terbaik diperlukan cara untuk membuang panas dari termoelektrik. Penelitian yang dilakukan oleh Permana (2006) dengan menggunakan medium air, sisi panas termoelektrik dapat mencapai $26,48^{\circ} \mathrm{C}$ sedangkan penelitian yang dilakukan oleh Sinaga (2016) sisi panas dapat mencapai $42,5^{\circ} \mathrm{C}$.

Diperlukan sebuah kotak yang dapat digunakan untuk menyimpan makanan namun juga memiliki sifat mengisolasi termal. Beberapa bahan dapat digunakan dan terpilih bahan styrofoam yang digunakan sebagai kotak pendingin. Dikarenakan sryrofoam memiliki konduktivitas termal yang rendah, terdapat sekat yang memisahkan styrofoam sebagai 
konstruksi utama dan kompartemen untuk meletakkan bahan makanan. Sekat antara kompartemen dengan styrofoam diisi dengan air yang menutup $\pm 80 \%$ kompartemen. Air yang digunakan berfungsi sebagai dinding termal dan mendinginkan sisi panas dari termoelektrik. Bahan yang digunakan untuk kompartemen adalah aluminium dengan ketebalan $1 \mathrm{~mm}$. konduktivitas termal styrofoam yang rendah dibuktikan oleh penelitian dari Hariady dkk, (2014) semakin banyak komposisi styrofoam dalam campuran dapat memperkecil konduktivitas termal dari bahan campuran, dan ini semakin diperkuat dengan campuran beton yang di padu padankan dengan styrofoam memberikan pengaruh terhadap konduktivitas beton (Mahdi dkk, 2019). Desain yang digunakan di dirancang seperti pada penelitian dari Putra dkk, (2014) Pemilihan aluminium karena aluminium memliki konduktivitas yang baik, dimana alumunium sebagai bahan utama dicampur dengan silica karbon dan alumina partikel dapat meningkatkan konduktivitas termal hingga 455,111 $\mathrm{k}\left(\mathrm{W} / \mathrm{m}^{\circ} \mathrm{C}\right)$. kemudian penelitian yang dilakukan oleh Sheng dkk (2019) penambahan aluminium pada suatu bahan juga menambah nilai konduktivitas termal, yakni dengan menambahkan aluminium filler pada bahan Erythritol meghasilkan nilai konduktivitas termal menjadi $3 \mathrm{~W} / \mathrm{m}^{-1} \mathrm{~K}^{-1}$.

Maka dengan komposisi bahan yang digunakan dapat dilakukan sebuah perncangan dengan memanfaatkan termoeletrik dengan tipe TEC1-12710 sebagai pengganti Freon sebagai sistem pendinginan alternatif dengan pengisolasian termal menggunakan medium air dan kontroller tegangan listrik.

\section{METODE PENELITIAN}

Metode penelitian yang dilakukan adalah dengan merancang kotak desain dari kotak pendingin dan pengaturan tegangan listrik yang masuk pada modul. Pemilihan bahan yang digunakan sebagai konstruksi utama yang digunakan sebagai kotak pendingin yakni menggunakan styrofoam dengan ukuran $50 \times 40 \times 30 \mathrm{~cm}$ dengan ketebalan $2 \mathrm{~cm}$, kemudian untuk kompartemen dipilih dengan menggunakan material plat aluminium dengan ketebalan $1 \mathrm{~mm}$ dibentuk menjadi sebuah kompartemen untuk meletakkan bahan uji. Modul termoelektrik yang digunakan adalah modul termoelektrik adalah tipe TEC1-12710 dengan datasheet sebagai berikut:

Tabel 1. Spesifikasi Modul Termoelektrik

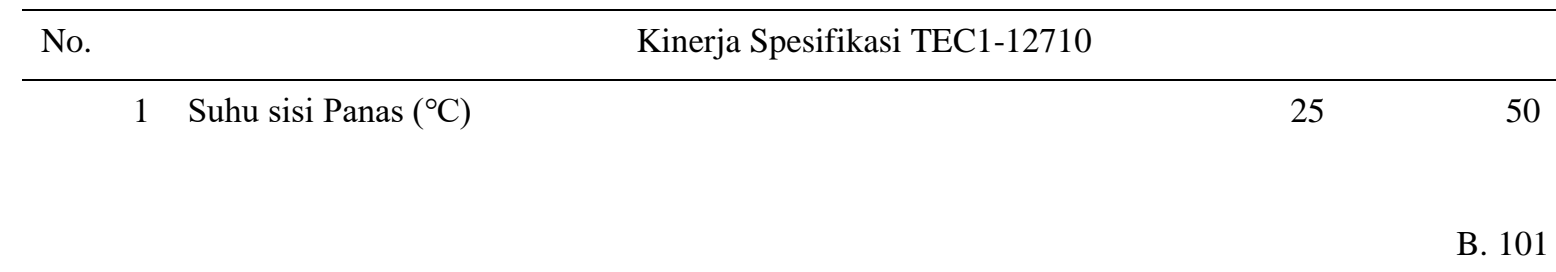


2 Qmax (Watts)

3 Delta Tmax $\left({ }^{\circ} \mathrm{C}\right)$

4 Imax (Ampere)

10,5

5 Vmax (Volts)

6 Hambatan (Ohm)

1,08

1,24

Sumber: alldatasheet.com/TEC1-12710

Input dari modul termoelektrik memiliki keterbatasan sebesar 17,4 V DC dan arus yang masuk maksimal yakni 10,5 A. sumber daya berasal dari listrik AC yang perlu di convert menjadi tegangan DC dengan menggunakan power supply $12 \mathrm{~V} 21 \mathrm{~A}$, pemilihan power supply berdasarkan kebutuhan dari modul termoelektrik yang membutuhkan tegangan sebesar 12 dengan arus maksimal sebesar 10,5 A. Stepdown DC 10A dengan input $12 \mathrm{~V}$ dengan dilakukan variasi nilai tegangan yang masuk sebesar $12 \mathrm{~V}, 8 \mathrm{~V}$, dan $6 \mathrm{~V}$. pengambilan data menggunakan data logger dengan sensor pengambil data menggunakan sensor termokopel. Pengambilan data dilakukan dengan enam perlakuan yakni:

- $12 \mathrm{~V}$ tanpa menggunakan beban

- $8 \mathrm{~V}$ tanpa menggunakan beban

- $6 \mathrm{~V}$ tanpa menggunakan beban

- $12 \mathrm{~V}$ menggunakan beban uji

- $8 \mathrm{~V}$ menggunakan beban uji

- $6 \mathrm{~V}$ menggunakan beban uji

Pengambilan data temperatur dilakukan di beberapa titik yakni sisi panas dan panas termoelektrik, lajur aliran kipas, dinding air, lingkungan lima titik di kompartemen, dan beban uji. Beban uji yang digunakan yakni air mineral dengan massa sebesar $330 \mathrm{ml}$. pengukuran nilai masuk arus pada modul dilakukan dengan menggunakan alat tang ampere DC.

Analisa dilakukan pada bagian daya yang masuk pada modul yakni dengan menggunakan persamaan sebagai berikut:

$p_{\text {in }}=V \times I$

Keterangan rumus:

$\mathrm{P}$ : Daya [W]

$\mathrm{V}$ : Nilai tegangan listrik [V]

I : Nilai arus [A] 
Analisa dilakukan untuk mengetahui pengaruh nilai tegangan terhadap arus yang masuk dan kemudian dianalisa dengan performa pendinginan dari termoelektrik. Kemudian dengan daya listrik yang telah diketahui dapat dilakukan penghitungan Harga COP dimana Harga COP adalah indikator yang digunakan untuk mengetahui kinerja dari mesin pendingin. Persamaan yang digunakan adalah sebagai berikut:

$$
C O P=\frac{Q_{\text {in }}}{P_{\text {in }}}
$$

Keterangan rumus:

COP : Coeffisient of performance

$Q_{\text {in }} \quad$ Kapasitas pendinginan [W]

$\mathrm{P}_{\text {in }} \quad$ : Daya listrik yang digunakan pada thermoelectric $[\mathrm{W}]$

Perhitungan harga COP dilakukan dengan menghitung kapasitas pendinginan dari kotak pendingin terhadap dingin yang dihasilkan kemudian dibagi dengan daya yang masuk pada modul termoelektrik. Setelah dilakukan pengambilan data maka dapat ditarik kesimpulan dari hasil penelitian dan saran untuk keberlanjutan dari penelitian.

\section{HASIL DAN PEMBAHASAN}

\section{Hasil Perancangan}

Perancangan dibuat dengan menggunakan aplikasi perancangan Autocad 2007 dengan menentukan dimensi dari styrofoam, kemudian perancangan kompartemen dengan mengurangi dimensi utama styrofoam untuk memberikan ruang untuk dinding air. Modul termoelektrik yang digunakan berjuamlah dua buah dirangkai secara paralel, dihubungkan dengan stepdown DC 10A untuk mengatur jumlah tegangan yang masuk pada modul termoelektrik. Kipas DC berjumlah dua dipasang secara paralel difungsikan untuk mendistribusikan dingin yang dihasilkan oleh termoelektrik, diparalelkan dengan pompa DC untuk membuang kalor dari sisi panas termoelektrik. Sumber tegangan yang digunakan 
adalah power supply $12 \mathrm{~V} 21$ A yang berfungsi untuk meng-convert listrik AC menjadi listrik DC.
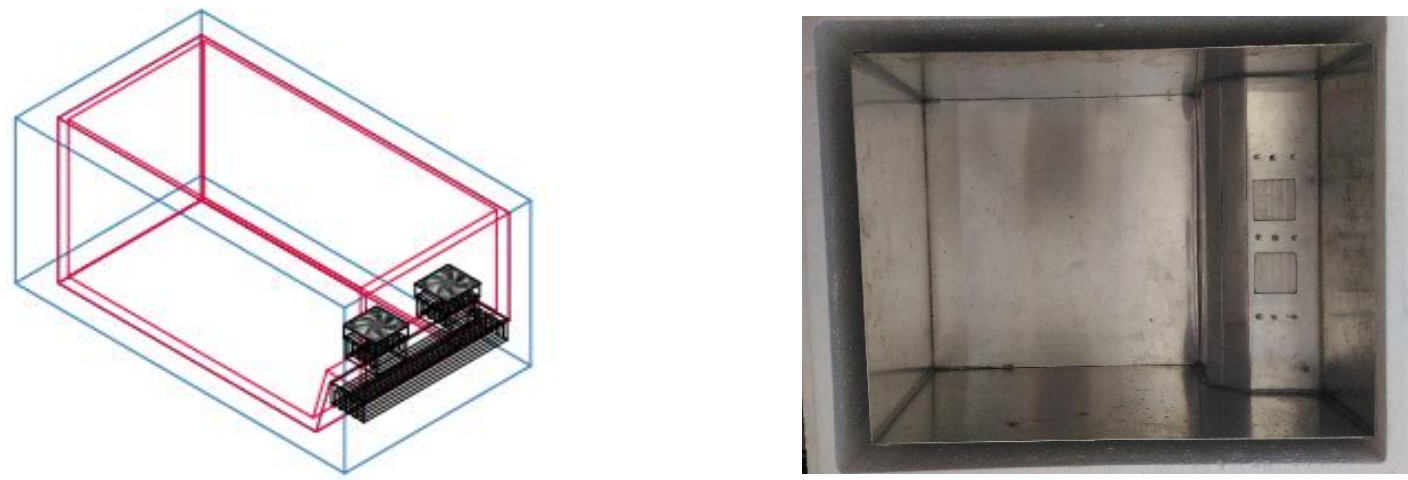

Gambar 1. Desain Coolcase

Sumber: Perancangan desain alat, 2020

\section{Kinerja mesin pendingin}

Pengujian dilakukan dengan meletakkan sensor termokopel di beberapa titik di sisi kompartemen, beban uji dengan botol air mineral $330 \mathrm{ml}$, sisi panas, sisi dingin, dinding air, dan lingkungan. Pengujian dilakukan untuk mendapatkan temperatur maksimal, didapatkan bahwa rerata waktu yang didapatkan selama satu jam. Pengujian dilakukan dengan enam perlakuan.

\subsection{Sisi Dingin Termoelektrik}

Sisi dingin adalah bagian yang memiliki fungsi untuk menyerap kalor yang ada pada ruangan kompartemen. Pengukuran dengan menggunakan sensor termokopel, pengujian dilakukan dengan perlakuan menggunakan beban dan tanpa beban. Nilai yang didapat adalah sebagai berikut:

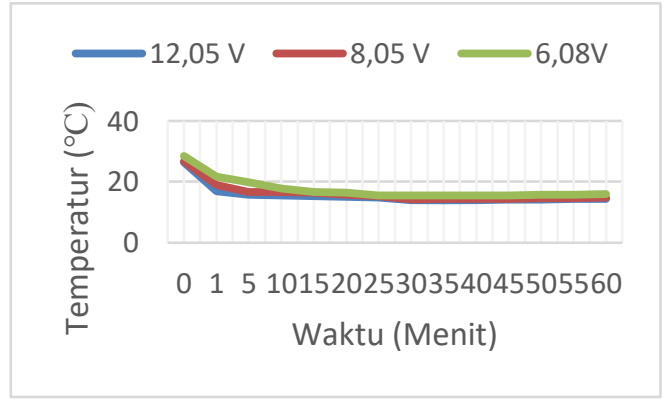

A

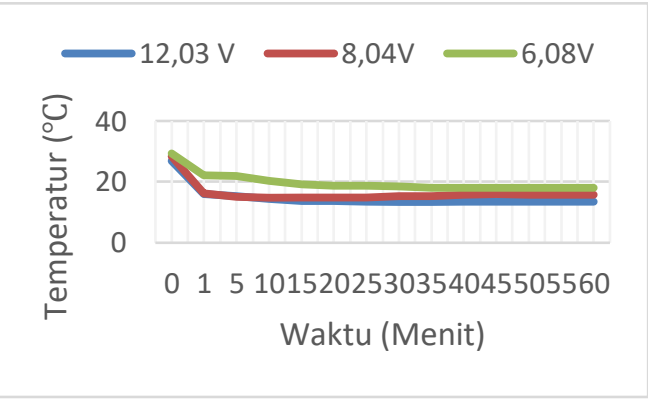

B

Gambar 2. Sisi Dingin Termoelektrik: (A) tanpa Beban, dan (B) dengan Beban Sumber: Pengolahan data, 2020 
Pada gambar 1 dan 2 terlohat sebuah kemiripan dalam perlakuannya. Pada perlakuan dengan tegangan masuk pada modul yakni $12 \mathrm{~V}$ memiliki performa yang baik dalam menyerap kalor. Penurunan nilai tegangan juga mempengaruhi nilai arus yang masuk sehingga mengganggu performa dari moduk tersebut. Temperatur terbaik dari keduanya dapat mencapai $14^{\circ} \mathrm{C}$ untuk tanpa beban, dengan menggunakan beban sisi dingin dapat mencapai temperatur $13,4^{\circ} \mathrm{C}$.

\subsection{Sisi Panas Termoelektrik}

Sisi panas adalah bagian yang memiliki fungsi untuk membuang kalor yang dihasilkan dari kerja termoelektrik. Pada bagian sisi panas diperlakukan perlakuan dengan mendinginkan sisi panas untuk memaksimalkan kinerja dari sisi dingin untuk menyerap kalor. Data yang didapat adalah sebagai berikut:

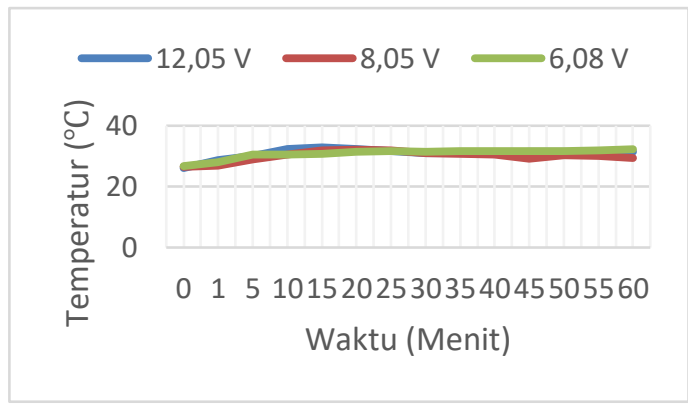

A

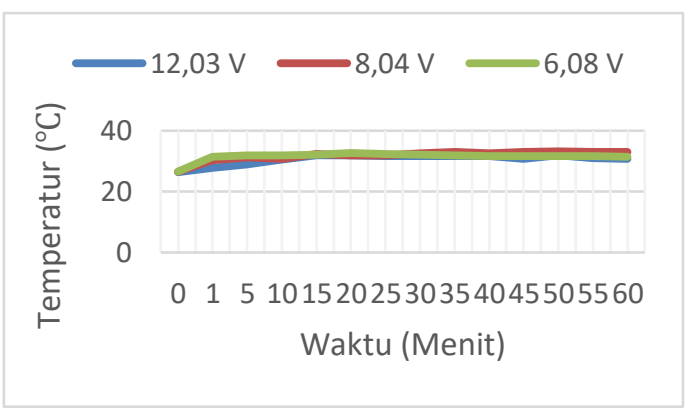

B

Gambar 3. Sisi Panas Termoelektrik: (A) tanpa Beban, dan (B) dengan Beban Sumber: Pengolahan data, 2020

Pada gambar 3 dan 4 terlihat temperatur keduanya berada pada interval $30^{\circ} \mathrm{C}$ hingga $35^{\circ} \mathrm{C}$. Secara teoritis semakin besar nilai tegangan dan arus yang masuk maka akan memperbesar temperatur panas namun hal itu perlu diperhatikan proses buang kalor dari sisi panas tersebut. Dengan menggunakan medium air. 


\subsection{Ruangan Kompartemen}

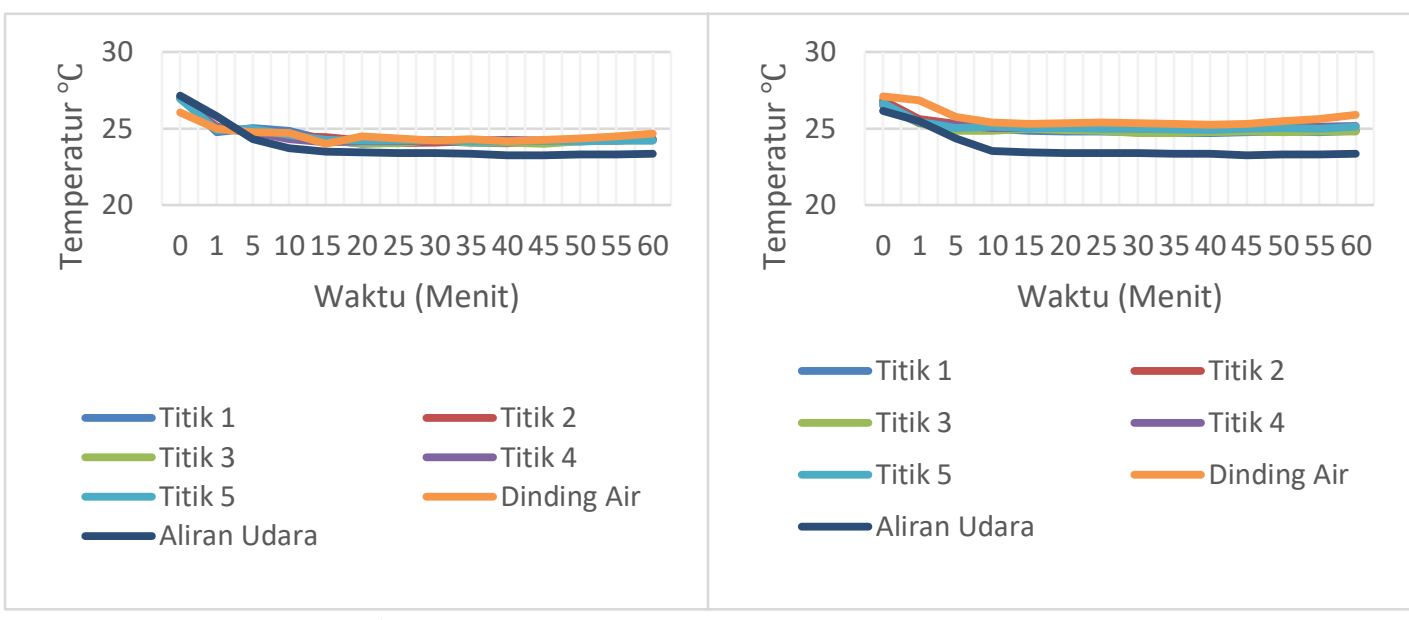

A

B

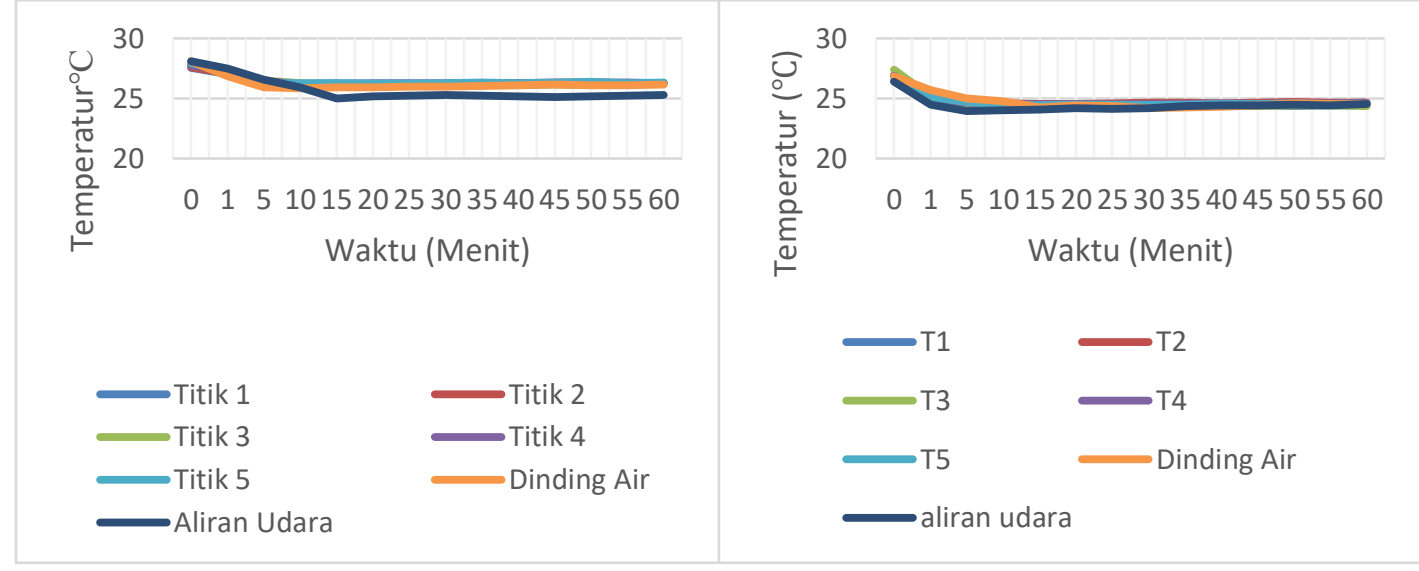

C

D

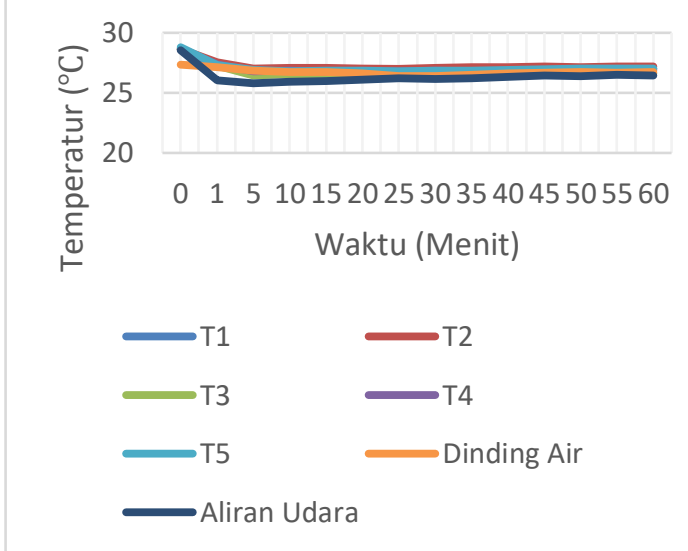

E
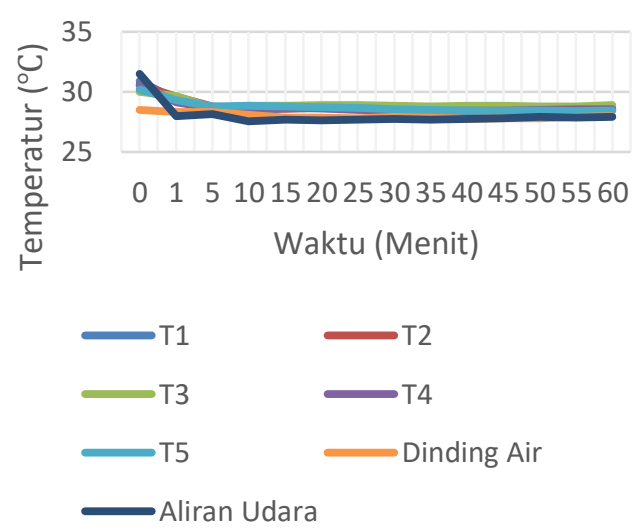

$\mathrm{F}$

Gambar 4. Ruangan Kompartemen dengan Beberapa Kondisi : (A) 12,05 V tanpa

Beban, (B) 8,05 V tanpa beban, (C) 6,08V tanpa beban, (D) 12,03 V dengan Beban,

(E) 8,04 V dengan Beban, (F) 6,08 V dengan Beban.

Sumber: Pengolahan data, 2020 
Pada ruang kompartemen dilakukan variasi tegangan input, dengan perlakuan variasi tegangan. Sensor termokoperl diletakkan di dinding - dinding kompartemen untuk mengetahui aliran dingin yang dapat dicapai dari hembusan kipas. Didapatkan rerata temperatur dalam kompartemen adalah $24,5^{\circ} \mathrm{C}$ pada tegangan $12,05 \mathrm{~V}$, pada tegangan input $8,05 \mathrm{~V}$ rerata temperatur $25,11^{\circ} \mathrm{C}$, dan pada tegangan input $6,08 \mathrm{~V}$ rerata temperatur mencapai $26,42^{\circ} \mathrm{C}$. Kemudian pada pengujian dengan menggunakan beban air mineral $330 \mathrm{ml}$ dua buah didapatkan bahwa pada tegangan input $12,03 \mathrm{~V}$ rerata temperatur yang dapat dicapai $24,69^{\circ} \mathrm{C}$, pada tegangan input $8,04 \mathrm{~V}$ rerata temperatur mencapai $27,03^{\circ} \mathrm{C}$, sedangkan pada tegangan input $6,08 \mathrm{~V}$ rerata temperatur mencapai $28,82^{\circ} \mathrm{C}$.

\subsection{Temperatur Beban Uji}

Beban uji yang digunakan dalam penelitian ini adalah air mineral dengan berat bersih $330 \mathrm{ml}$ berjumlah dua buah, dengan sensor termokopel diletakkan didalam air mineral pada botol. Didapatkan data sebagai berikut:

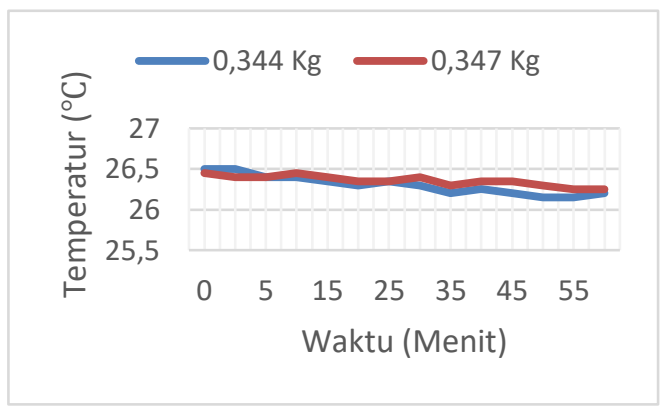

A

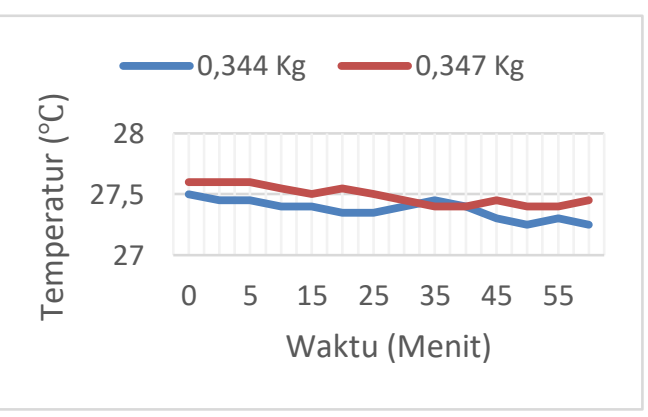

B

Gambar 5. Temperatur Beban Uji dengan Variasi Tegangan: (A) 12,03 V, (B) 8,04

$$
\mathrm{V}, \text { (C) 6,08 V. }
$$

Sumber: Pengolahan data, 2020 
Pada keriga grafik diperlihatkan bahwa pergerakan grafik terlihat fluktuatif, penurunan temperatur hanya mencapai satu derajat celcius hal ini terjadi karena distribusi udara dingin kurang baik sehingga tidak dapat mendinginkan beban uji dengan maksimal. Temperatur terendah didapatkan dengan masukkan nilai tegangan $12,03 \mathrm{~V}$ yakni mencapai $26,3^{\circ} \mathrm{C}$. Diikuti dengan tegangan yang masuk pada nilai $8,04 \mathrm{~V}$, dilanjutkan dengan tegangan 6,08 V. Ketiganya menunjukan trend yang terus mengalami penurunan.

\subsection{Harga COP}

Harga COP adalah salah satu indikator yang digunakan untuk menunjukkan kinerja mesin pendingin. Dari tiga perlakuan tanpa beban terlihat bahwa mesin pendingin mengalami penurunan Harga COP. Harga COP terbaik pada pengujian tanpa beban didapatkan pada tegangan 6,08 V yakni 1,19 hal ini terjadi karena daya yang dikeluarkan semakin kecil dibandingkan dengan input dari tegangan yang lain. Sedangkan pada perlakuan dengan beban uji nilai COP tertinggi terdapat pada input tegangan 6,08 V yakni 0,0012, hasil ini memiliki kesamaan dengan perlakuan tanpa beban.

\section{KESIMPULAN}

Kesimpulan setelah pengujian didapatakan Sistem pendinginan dengan menggunakan modul termoelektrik telah diuji kinerjanya. Oleh karena dapat ditarik kesimpulan sebagai berikut:

1. Kinerja penurunan temperatur terbaik berada pada tegangan kisaran $12 \mathrm{~V}$ namun Harga COP tertinggi terjadi pada tegangan kisaran $6 \mathrm{~V}$ dengan harga COP 1,19 tanpa beban uji dan 0,012 dengan beban uji. Berdasarkan pengujian didapatkan bahwa terhadap kinerja dari termoelektrik berbanding lurus dengan jumlah nilai tegangan dan arus listrik yang masuk pada modul.

2. Temperatur terendah sisi dingin yang dapat dicapai tanpa beban mencapai $14^{\circ} \mathrm{C}$ dengan temperatur dalam ruangan kompartemen dapat mencapai $24,5^{\circ} \mathrm{C}$. Pengujian dengan menggunakan beban uji, temperatur terendah yang dapat dicapai yakni $13,4^{\circ} \mathrm{C}$ dan temperatur ruangan kompartemen mencapai $24,56{ }^{\circ} \mathrm{C}$. 
3. Perlu dilakukan pengkajian ulang dalam perancangan untuk mengatasi buang panas yang ada pada termoelektrik dan distribusi dingin sehingga kotak pendingin dapat diaplikasikan menjadi pengganti kotak pendingin konvensional.

\section{DAFTAR PUSTAKA}

Delly, J. M. Hasbi, \& Alkhoiron, I. F. (2016). Studi Penggunaan Modul Thermoelektrik Sebagai Sistem Pendingin Portable. Jurnal Ilmiah Mahasiswa Teknik Mesin. Vol. 1, No. 1. Hal 51 - 52. e-ISSN:2502-8944.

Etminan. M., Highwood, E. J., Laube, J. C., McPheat, R., Marston, G., Shine, K. P., \& Smith, K. M. (2014). Infrared Absorption Spectra, Radiative Efficiencies, and Global Warming Potentials of Newly-detected Halogenated Compounds: CFC - 113a, CFC - 112, and HCFC - 133a. Reading, U.K. Atmosphere 2014, 5, 473 - 483; doi:10.3390/atmos5030473.

Fauzan. I. (2015). Analisis Perbandingan Evaporator Kulkas (Lemari Es) Dengan Menggunakan Refrigerant R-22 dan R-134A. Jakarta. Jurnal Teknik Mesin (JTM): Vol. 04, No. 3, Oktober 2015.

Hariady. S., Fauzie, M.A., dan Sukarmansyah. (2014). Kaji Eksperimental Kemampuan Daya Hantar Kalor Campuran Styrofoam, Kulit Jengkol, dan Semen Putih Sebagai Alternatif Bahan Isolator. Palembang. Jurnal Desiminasi Teknologi, Vol. 2, No. 2, Juli 2014.

Krisnadwi. (2015). CFC Sebagai Penyebab Efek Rumah Kaca. Bisakimia. https://bisakimia.com/2015/11/19/cfc-sebagai-penyebab-efek-rumah-kacal. 05/12/2019 pukul 13.14.

Maulana, A. (2010). Penggunaan BPO (Bahan Perusak Ozon) di Provinsi Jakarta dari Sektor Refrigerator. Jakarta: APRAL.

Mahdi H. A., Jasim, K. A., \& Shaban. A. H. (2019). Manufacturing and Improving the Characteristics of The Isolation of Concrete Composites by Additive Styrofoam Particulate. Athens, Greece. Technologies and Materials for Renewable Energy, Environment and Sustainability, ScienceDirect Procedia Energy 157 (2019) 158-163.

Nulhakim, L. (2017). Uji Unjuk Kerja Mesin Pendingin Ruangan Berbasis Thermoelectric Cooling. Jurnal SIMETRIS, Vol. 8, No. 1. ISSN: 2252-4983.

Permana, P. (2006). Rancang Bangun dan Kajian Sistem Pembuangan Panas dari Ruang Pendingin Sistem Termoelektrik untuk Pendinginan Jamur Merang. Skripsi. Institut Pertanian Bogor.

Pourhedayat. S. (2018). Application of Thermoelectric as an Instant Running-water Cooler; Experimental Study Under Different Operating Conditions. Urmia, Iran. Elsevier, ScienceDirect. Applied Energy 229 (2018) $364-374$.

Putra. I.D., Baheramsyah, A., dan Cahyono, B. (2014). Modifikasi Coolbox dengan Insulasi Pendinginan Freon pada Ruang Muat Kapal Ikan Tradisional. JURNAL TEKNIK POMITS Vol. 3, No. 1, ISSN: 2337-3539 (2301-9271 Print).

Sheng. N., Dong, K., Zhu, C., Akiyama, T. dan Nomura, T. (2019). Thermal Conductivity Enhancement of Erythritol Phase Change Material with Percolated Aluminium Filler. Sapporo, Japan. Material Chemistry and Physics 229 (2019) 87-91.

Sinaga, A.S. (2016). Rancang Bangun Pendingin Termoelektrik Menggunakan Elemen Peltier Tipe TEC1-12706. Skripsi. Politeknik Negeri Jember. 
Wirayudha. B. S. (2012). Pengembangan Alat Cryosurgery Prototipe V Berbasis Termoelektrik Bertingkat. Depok: Universitas Indonesia. Fakultas Teknik. Departemen Teknik Mesin. 